\title{
Call for Review Papers: Tissue Engineering, Part B
}

\author{
Co-Editors-in-Chief: Katja Schenke-Layland, MSc, PhD; University Women's Hospital at Eberhard Karls \\ University Tübingen, Germany; Heungsoo Shin, PhD; Hanyang University, Korea
}

As we continue to navigate the disruption of the COVID-19 outbreak, Tissue Engineering, Part B: Reviews (IF 6.512) would like to personally invite all researchers in the field to submit their review papers for prompt and thorough consideration in the journal.

Many researchers are currently experiencing multiple changes in their academic routines as presented by the COVID-19 pandemic. This is why the Editors-in-Chief of Tissue Engineering, Part B: Reviews would like to issue an open call for review articles to be given thorough, expedited review and consideration in the journal. Reviews of exceptional merit will receive an additional benefit of a global press release announcement highlighting their research to the global Tissue Engineering audience around the world, and may also qualify for a "Best Paper Award" at the end of the calendar year, to be presented at the TERMIS-Americas meeting in December 2020.

Our intent is to give tissue engineering and regenerative medicine researchers every opportunity to continue to leverage their research even if

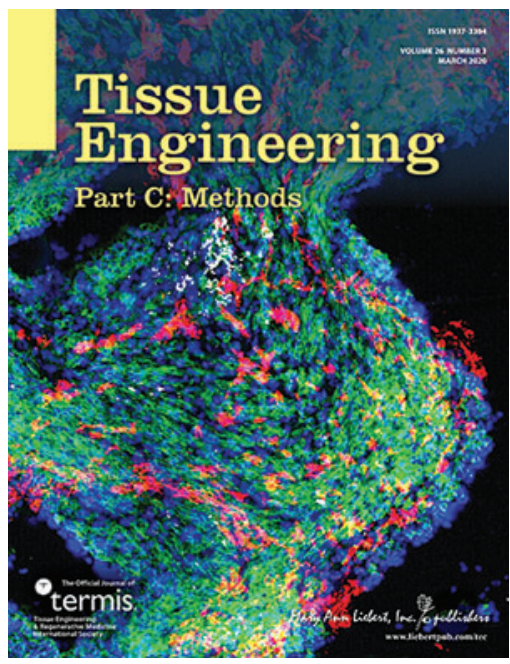
directly affected by the COVID-19 outbreak. Tissue Engineering has consistently served as an influential and impactful resource in the field and the journal will remain a core venue for continued research and growth during times of crisis.

Submit your review today at https://mc.manuscriptcentral.com/ten

Please refer to our Instructions for Authors prior to submission at www.liebertpub.com/ten

If you have any questions, please send all presubmission queries to Drs. Katja Schenke-Layland and Heungsoo Shin.

\section{Visit the Instructions for Authors: www.liebertpub.com/ten}

\section{Submit your paper for peer review online: https://mc.manuscriptcentral.com/ten}

